\title{
Counterconditioning of memory in rats
}

\author{
RICK RICHARDSON, DAVID C. RICCIO, and DREW SMOLLER \\ Kent State University, Kent, Ohio
}

\begin{abstract}
Two experiments examined the counterconditioning of an aversively motivated response in rats. Presentation of a highly palatable sugar solution (maltose in Experiment 1; sucrose in Experiment 2) to thirsty rats was used as the counterconditioning treatment. In Experiment 1 , the counterconditioning procedure was found to be effective in modifying both a newly acquired and a cue-reactivated fear memory. In Experiment 2, the counterconditioning effect was shown to occur when the fear memory was reactivated with a noncontingent exposure to the unconditioned stimulus rather than the conditioned stimulus. This outcome supports the interpretation of counterconditioning as a modification of some central representation of the original training memory, rather than the acquisition of a competing peripheral response. The methodological implications of the present approach to counterconditioning are considered.
\end{abstract}

The goal of many behavioral studies is to alter the hedonic value of some stimulus. One procedure for producing such change is counterconditioning, in which a subject's response to a stimulus of one affective value is modified by presenting that stimulus in conjunction with one having different (i.e., opposite) emotional significance. Traditionally, there have been two very distinct types of counterconditioning paradigms, depending upon whether the target stimulus was the unconditioned stimulus (US) or the conditioned stimulus (CS). An example of a counterconditioning experiment directed at altering the US value is provided by Pearce and Dickinson (1975). These investigators found that rats given repeated shock-food pairings showed less suppression of an ongoing operant behavior to a light subsequently paired with the shock than did animals exposed to food and shock in an unpaired fashion prior to the light-shock pairings. That is, the pairing of two USs was found to alter the effectiveness of at least one of them in a subsequent conditioning procedure. Although there seems to be some question concerning the symmetry of counterconditioning effects with this technique (see Lovibond \& Dickinson, 1982), it does appear to be a reliable technique for altering the value of aversive stimuli (Dearing \& Dickinson, 1979).

In the other type of paradigm, a conditioned fear stimulus is typically presented in conjunction with an appetitive reward. Pairing the aversive CS with the appetitive US is expected to produce greater reductions in fear of the CS than that produced by mere exposures to the CS (i.e., extinction). For example, Hunsicker, Nelson, and

This research was supported in part by NIMH Grant MH37535 to D.C.R. During preparation of this report R.R. was supported by N.R.S.A. MH09179 from NIMH. Experiment 1 of this report was part of R.R.'s master's thesis and was presented at the annual meeting of the Eastern Psychological Association, Baltimore, April 1982. The authors would like to thank Jeff Cabosky for his assistance with Experiment 1 . Requests for reprints may be sent either to David C. Riccio, Department of Psychology, Kent State University, Kent, OH 44242, or to Rick Richardson, who is now at the Psychology Department, Princeton University, Princeton, NJ 08544.
Reid (1973) found that rats given rewarding intracranial stimulation during a forced exposure to a previously shocked location exhibited less avoidance of that location on a subsequent test than did subjects given the forced exposure only. As noted by Dearing and Dickinson (1979), most studies of counterconditioning have been of the type in which an aversive CS is presented in conjunction with an appetitive US, and the focus of this study is on issues related to that paradigm.

Although there have been numerous successful reports of counterconditioning (e.g., Davison, 1968; Reid, 1973; Richardson, Riccio, Jamis, Skozcen, \& Cabosky, 1982; E. H. Wilson \& Dinsmoor, 1970), a number of failures to observe a counterconditioning effect have also been reported (e.g., Delprato \& Jackson, 1973; G. T. Wilson, 1973). A recent study (Capaldi, Vivieros, \& Campbell, 1983) even challenged whether counterconditioning can be considered as a bona fide phenomenon. Admittedly, there are, as pointed out by Capaldi et al. (1983) and G. T. Wilson and Davison (1971), several potentially confounding characteristics of the typical counterconditioning procedure. These troublesome characteristics, however, could simply make it more difficult to observe counterconditioning and need not apply at all to the actual occurrence of this phenomenon. (These issues will be discussed in more detail in the General Discussion.) Thus, in order to examine the occurrence of counterconditioning these potentially confounding features of the experimental procedure must be eliminated. The present study consisted of two experiments using a slight variant of the traditional counterconditioning procedure. We believe that both of these experiments clearly demonstrate the occurrence of counterconditioning in rats.

\section{EXPERIMENT 1}

\section{Method}

Subjects. Thirty-eight adult male rats (purchased from the Holtzman Co.), 100-200 days of age, served as subjects. The rats were housed singly and were ear-punched for identification purposes. 
Food was available ad lib. Water was removed from all animals' cages 3 days prior to training.

Apparatus. The training apparatus was a $38 \times 18 \times 20 \mathrm{~cm}$ Plexiglas box. The apparatus was divided into two equal compartments, one painted black and one painted white. A black lid covered the black compartment and a clear lid covered the white compartment. A $7 \times 7.5 \mathrm{~cm}$ guillotine doorway separated the two compartments. A 15-W light suspended $30 \mathrm{~cm}$ above the center of the white compartment provided the only illumination in the experimental room. The floor consisted of $.25-\mathrm{cm}$ stainless steel grids spaced $1 \mathrm{~cm}$ apart. The subjects' behavior was monitored via a tilted mirror placed under the center of the apparatus. A scrambled shock from a highimpedance shock source (Campbell \& Teghtsoonian, 1958) could be delivered to the black compartment of the apparatus. White noise masked extraneous sounds during training and test sessions.

Procedure. For 3 days, the subjects received a $10 \%$ (weight/volume) maltose (65\% industrial grade M, Fischer Scientific Co.) solution for $15 \mathrm{~min}$. They were deprived of water for the other $23.75 \mathrm{~h}$. All subjects were also handled for 2-3 min on each of these 3 days. This preexposure to maltose familiarized the subjects with this substance and ensured that they were not neophobic on the day of counterconditioning. On Day 4, all animals received Pavlovian differential fear conditioning. This consisted of an 8-min session during which the animal was placed in the black compartment for two separate 2-min periods and in the white compartment for two separate 2-min periods (a sequence of black, white, black, white was used). During each period in the black compartment, six 1-sec 150-V inescapable shocks were delivered. These shocks occurred at irregular intervals, that is, after 10, 30, 40, 70, 90, and $100 \mathrm{sec}$ in the compartment. No shocks were administered on the white side of the apparatus.

Animals were randomly assigned to one of four different treatment conditions. The subjects in two groups $(N s=10)$ were given 5 min access to maltose (the counterconditioning agent) in their home cages outside the experimental room at one of two intervals after training. Maltose was given either immediately $(5-10 \mathrm{sec})$ or $240 \mathrm{~min}$ after training. The subjects in the other two groups were not exposed to maltose at any time on the day of training, but were given 5 min access to tap water in their home cages 3-4 h after training.

On the day following fear conditioning, subjects that had not received maltose after training were returned to the experimental room and given a brief $(30 \mathrm{sec})$ nonreinforced exposure to the black compartment. This reexposure was intended to reactivate the training memory. After this reactivation treatment, the subjects were given

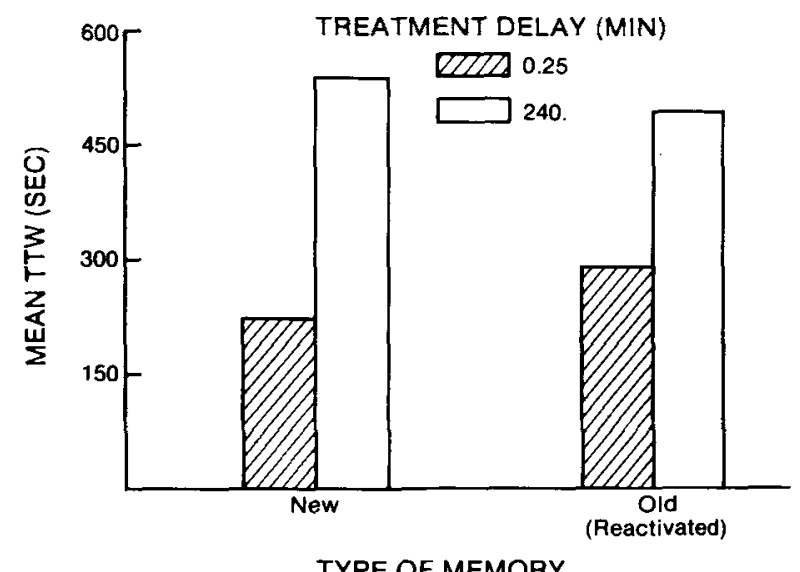

Figure 1. Total time in safe (white) compartment when counterconditioning was administered immediately $(0.25 \mathrm{~min})$ or with a 4-h delay following newly acquired or old (reactivated) learning.
5 min access to maltose in their home cages outside the experimental room either immediately $(5-10 \mathrm{sec} ; N=8)$ or $240 \mathrm{~min}$ later $(N=10)$.

Thus, the experimental design consisted of four groups of subjects that were exposed, after one of two delays, to a counterconditioning treatment. Two of these groups had an earlier memory reactivated prior to counterconditioning (i.e., the memory was “old"), whereas the other two groups had just acquired the memory (i.e, it was "new"). This allowed us to compare the susceptibility of old reactivated and newly acquired memories to counterconditioning.

Retention testing occurred the day after counterconditioning for all subjects. A passive avoidance measure of fear was employed. The subjects were placed on the white side of the apparatus facing away from the closed door. Ten seconds later, the door was removed, which permitted access to the black compartment. The test session lasted for $10 \mathrm{~min}$ and two measures of fear were recorded: (1) time taken to enter (with all four paws) the black compartment for the first time (i.e., latency), and (2) total amount of time spent on the white side (TTW). No shocks were administered during testing. At the time of test, the experimenter was blind with respect to the treatment condition of the subject.

\section{Results}

Because analysis of the latency and TTW data produced the same general pattern of results, only the TTW data will be presented. An ANOVA of the TTW data revealed a significant effect of delay $[F(1,34)=91.85, p<$ $.0001]$, no effect of type of memory $[F(1,34)<1.0]$, and no interaction $[F(1,34)=3.36, p>.05]$. As can be seen clearly in Figure 1, subjects given the counterconditioning agent immediately after training or reactivation exhibited significantly less fear of the black compartment than did subjects given the counterconditioning agent 240 min after training or reactivation $(p s<.05$, Tukey test).

This modification of the hedonic value of the CS was accomplished in the absence of the physical stimuli of training, suggesting that the counterconditioning treatment influenced a representation of the CS (cf. Rescorla, 1973, 1974). Consistent with numerous studies on the timedependent vulnerability of memory to amnestic treatment (e.g., McGaugh, 1966; Riccio \& Richardson, 1984), exposure to maltose was far more effective in modulating the conditioned fear when given shortly after acquisition (or reactivation) than after a long delay. Under the conditions employed here, there was no evidence of a difference between newly acquired and old reactivated target information with respect to their modifiability through counterconditioning.

\section{EXPERIMENT 2}

One interpretation of the results of Experiment 1, as well as the other work from this lab on counterconditioning (see Richardson, Riccio, Jamis, et al., 1982), is that some central representation of the original training memory is modified by the counterconditioning treatment. That is, the subjects' representation of the hedonic value of the black compartment is altered as a result of the counterconditioning procedure. However, a very different interpretation of the observed effects of the countercondi- 
tioning treatment could be offered. This alternative account, the peripheral mediation view, postulates that during counterconditioning, fear memories are not modified, but subjects acquire a new motor response that competes with the expression of fear. More specifically, this view argues that on the second day the rats acquire a conditioned appetitive response to the black compartment through Pavlovian trace conditioning of the black with maltose. Because the conditioned appetitive response could elicit approach behavior, the poor retention performance exhibited by counterconditioned subjects would be due to the introduction of interfering learning (i.e, conditioned approach response) rather than modification of the original training memory. (In the traditional learning areas, attempts to account for apparently central or cognitive effects through peripherally mediated changes have, of course, been common.)

However, this competing-response explanation is viable only for the reactivated memory condition. It will be recalled that for the new learning condition subjects were confined to the white compartment during the last $2 \mathrm{~min}$ of training. Thus, any possible trace appetitive conditioning would be between the white compartment and maltose for those subjects counterconditioned immediately after training. This, of course, would work against the occurrence of counterconditioning. Although the competingresponse hypothesis clearly cannot account for the counterconditioning effect seen in those subjects given maltose immediately after training, it does remain a possible explanation for the effect seen when old memory was reactivated. As exposure to the black is necessary only to reactivate memory, using some other treatment to reactivate the earlier acquired memory should eliminate this source of interpretative difficulties. For instance, in several studies noncontingent footshock has been used to reactivate an earlier established memory, making it susceptible to retrograde amnesia (see Richardson, Riccio, \& Mowrey, 1982). The same procedure was employed in the current experiment, except that a counterconditioning treatment, rather than an amnestic agent, was given after the noncontingent footshock (i.e., reactivation).

\section{Method}

Subjects. Twenty-five naive adult male rats (78-86 days of age) purchased from the Holtzman Co. served as subjects. All subjects were housed individually and were ear-punched for identification purposes. Food was available ad lib, although access to liquids was restricted starting 7 days before training.

Apparatus. The training and testing apparatus employed in Experiment 1 was used. In addition, a $21 \times 18 \times 19 \mathrm{~cm}$ unpainted wooden box, with a clear Plexiglas lid, was used to administer noncontingent footshock (NCFS). Administration of NCFS occurred in the same room as training, but with the white noise turned off and overhead fluorescent lights, rather than a 15-W light bulb, providing the illumination in the room.

Procedure. For 6 days, all subjects received a 30-min exposure to a $10 \%$ (weight/volume) sucrose solution. Subjects were water deprived the other $23.5 \mathrm{~h}$. All subjects were handled for 2-3 min on each of the preexposure days. Again, this preexposure was intended to familiarize subjects with the sucrose and reduce any neo- phobic tendencies towards that substance. Sucrose was employed in this experiment, instead of maltose, in order to provide some generality with respect to effective counterconditioning agents. On Day 7, all subjects received Pavlovian differential fear conditioning. This conditioning session was similar to that of Experiment 1, except that session length was reduced to $2 \mathrm{~min}$. The subject was initially placed on the black side for $30 \mathrm{sec}$. During this time, two inescapable footshocks $(150 \mathrm{~V} / \mathrm{sec})$ were delivered (after 10 and $22 \mathrm{sec}$ ). At the end of this 30 -sec period, the subject was placed on the white side for $30 \mathrm{sec}$ and no shocks were delivered. This discriminative sequence was then repeated. All subjects received $30 \mathrm{~min}$ access to tap water 3-4 h after training.

On the day following training, the subjects were randomly assigned to one of three groups ( $N \mathrm{~s}=8$ or 9 ). Two groups received NCFS $(150 \mathrm{~V} / \mathrm{sec})$, after which they were kept in the experimental room for $5 \mathrm{~min}$. One group (immediate sucrose) was exposed to sucrose during this 5-min period and the other (delayed sucrose) was not. Both groups received $30 \mathrm{~min}$ access to the sucrose solution 3 to $4 \mathrm{~h}$ after NCFS. The third group of subjects (retention controls), which had not received NCFS, also received $30 \mathrm{~min}$ access to sucrose at this time.

All subjects were tested $48 \mathrm{~h}$ after training. The test procedure wis the same as that used in Experiment 1 .

\section{Results}

Sucrose intake. Analysis of intake data with the Wilcoxon matched-pair signed-ranks test revealed several findings of interest. First, subjects in each of the three groups increased their intake of the $10 \%$ sucrose solution over days (Day 1 , vs. Day 6 , all $T \mathrm{~s}=0, p<.01$ ). Furthermore, all subjects showed a decrease in intake when tap water was given instead of sucrose (Day 6 vs. Day 7 , all $T \mathrm{~s}=0, p<.01$, and an increase when sucrose was given again (Day 7 vs. Day 8 , all $T s=0$, $p<.01$ ). These data are depicted in Table 1 .

Separate ANOVAs on the sucrose intakes of each of the three groups on Day 1 and Day 6 (the first and last sucrose preexposure days) and Day 8 (counterconditioning day) were all nonsignificant [largest $F(2,22)=2.64$, $p>$.05]. Thus, subjects in the three different treatment conditions did not differ at any time in their intake of sucrose.

Because consumption of a highly palatable substance, sucrose, was intended to modify an earlier acquired fear memory, any adverse effects of NCFS on this consummatory behavior would, of course, be of concern. Thus, latency to begin licking after NCFS and the amount consumed during the 5-min exposure were recorded for subjects in the immediate sucrose group. Median latency to lick was $3 \mathrm{sec}$ and median amount of sucrose consumed was $7 \mathrm{ml}$. Clearly, the extended regimen of limited access to liquid led to animals' contacting the sipper tube

Table 1

Mean Intakes of Sucrose Across Days

\begin{tabular}{lcccc}
\hline & Day 1 & Day 6 & Day 7* & Day 8 \\
\hline Immediate sucrose & 16 & 28 & 19 & 28 \\
Delayed sucrose & 19 & 28 & 22 & 29 \\
Retention control & 22 & 29 & 20 & 30 \\
\hline
\end{tabular}

*Water was given on Day 7. 
as soon as it was attached and licking almost continuously during the exposure period.

Retention measures. Separate ANOVAs on the test latency and TTW measures were both significant $[F(2,22)$ $=7.16$ for latency; $F(2,22)=9.77$ for TTW; both $p s<.001]$. Because subsequent analysis with these two measures resulted in similar patterns of results, only the TTW data are presented (see Figure 2). Pairwise comparisons with the Tukey test demonstrated that subjects given sucrose immediately after NCFS had significantly less fear of the black compartment than did subjects given sucrose 3-4 h after NCFS or subjects not exposed to NCFS at all $(p \mathrm{~s}<.05)$. These latter two groups did not differ.

\section{Discussion}

The results of this experiment suggest that counterconditioning of memory is a central, rather than peripheral, process. The effects of the counterconditioning treatment are not simply due to approach behavior toward conditioned appetitive stimuli (the black compartment) that results from temporal proximity of the black side and a palatable substance. Reactivating the earlier acquired fear memory by exposing subjects to the US (footshock) noncontingently rather than by a nonreinforced cue exposure lessens the viability of the competing-learning hypothesis of the counterconditioning effect. The results of this experiment also show that a palatable flavor other than maltose (i.e., sucrose) can be employed as a counterconditioning agent in this preparation.

\section{GENERAL DISCUSSION}

The present findings provide evidence that a counterconditioning procedure can modify retention of a previously acquired fear response. These experiments suggest that counterconditioning affects the central representation, or hedonic value, of the target information, rather than producing competing responses that interfere with the measured behavior. Furthermore, these data indicate that counterconditioning need not be limited to direct juxtaposition of the CS with a new US, but can also be achieved by reactivating a memorial representation of the target stimulus prior to US exposure. Inasmuch as reactivation was achieved by noncontingent presentation of the training US (Experiment 2) as well as the CS (Experiment 1), extinction exposure was not a necessary condition for the counterconditioning effect.

From a more general perspective, the finding that target information was vulnerable to the counterconditioning manipulation in a time-dependent fashion (see also Richardson, Riccio, Jamis, et al., 1982) is consistent with other evidence that the state of activity of memory is an important determiner of its modifiability. Thus, the temporal gradient in counterconditioning is reminiscent of the gradient of memory impairment that results from administration of retrograde amnestic agents (see, e.g., Riccio \& Richardson, 1984, for a review). Although we expect that the mechanisms producing change in these instances are fundamentally different, both appear to depend on new or old memory's being in, or being returned to, an active state.

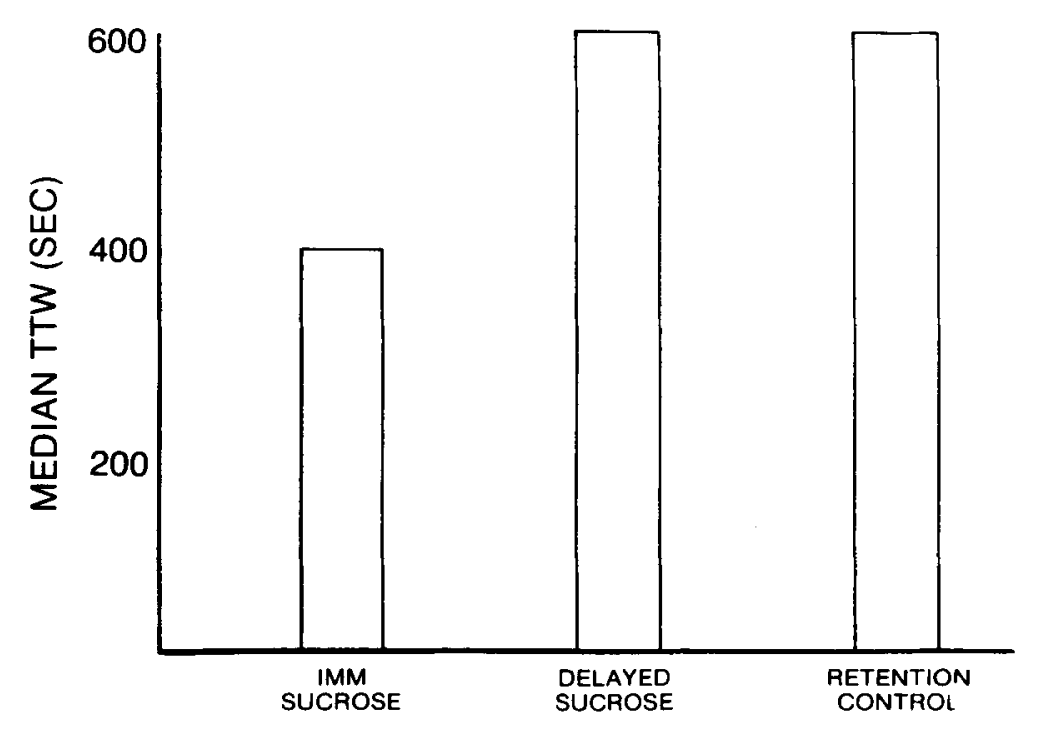

\section{TREATMENT CONDITION}

Figure 2. Total time in safe compartment for groups receiving counterconditioning treatment (sucrose) either immediately or several hours after a noncontingent footshock to reactivate previously conditioned fear. Retention controls received sucrose but not the reactivating footshock. 
The results of this study bear on several methodological problems that have complicated interpretation of traditional counterconditioning studies. Consider a typical paradigm in which subjects are given a positive event (e.g., food or rewarding brain stimulation) during a forced exposure to a stimulus that had previously been conditioned to elicit fear. Some studies have found this counterconditioning procedure to be more effective than an extinction exposure (Hunsicker et al., 1973; E. H. Wilson \& Dinsmoor, 1970), but others have not (Delprato \& Jackson, 1973), and some have even concluded that there is no bona fide counterconditioning process (Capaldi et al., 1983). At least three different explanations have been offered to account for the failures to observe a counterconditioning effect. For example, administration of the counterconditioning agent (e.g., food) during the forced exposure to the fear stimulus could alter the amount of attention subjects pay to that stimulus (see G. T. Wilson \& Davison, 1971); that is, subjects in the counterconditioning group could pay more attention to the food stimuli (and eating) than to the fear stimulus. In an extreme example, subjects in the counterconditioning group could fail to attend to the fear stimulus to such an extent that they are functionally similar to subjects given the counterconditioning agent alone (i.e., not even exposed to the fear stimulus). This, of course, would lessen the likelihood of obtaining the counterconditioning effect. A second potential problem resulting from the traditional counterconditioning procedure is the possible introduction of frustration at test (see Capaldi et al., 1983). Frustration may be introduced if subjects form an association between the counterconditioning agent (e.g., food) and the location at which forced exposure to the fear stimulus occurs. For example, consider the situation in which rats are initially trained to make a one-way avoidance response (to a tone stimulus) and then are given food while confined to the shock compartment with tone present but no shock. When subsequently tested for fear of the tone stimulus, subjects given food during the forced exposure sometimes respond as vigorously as subjects not given the counterconditioning agent during the forced exposure. Although this outcome is the opposite of what would be expected from a counterconditioning perspective, the result may not reflect a failure in counterconditioning. During the forced exposure to the fear stimulus, subjects in the counterconditioning group could have formed an association between the shock compartment and food. The absence of food during testing could then elicit frustration, which has been shown both to energize behaviors (Amsel \& Roussel, 1952) and to serve as a negative reinforcer producing escape conditioning (Daly, 1969). Thus, subjects in the counterconditioning group in this type of experiment may continue responding to the tone because of frustration-related increases in activity levels, not because the counterconditioning process itself is ineffective. A third methodological complication with the traditional counterconditioning procedure is context-specific extinction (Capaldi et al., 1983). Bouton and Bolles (1979) clearly demonstrated that extinction of an avoidance response in rats was specific to the context in which extinction took place; that is, the subjects showed little evidence of extinction if extinction and test trials were administered in two distinctively different environmental contexts. Similarly, the presence of the US during the counterconditioning treatment may provide a distinctive context that differs from that present at testing. Subjects confined in the presence of food (the counterconditioning agent) to a compartment in which shock had previously been given might still exhibit conditioned fear at test when no food is present. Indeed, Capaldi et al. (1983, Experiment 3) demonstrated context-specific extinction by manipulating the presence/absence of food pellets.

Clearly, there are a number of potential methodological problems with the procedures traditionally used to study counterconditioning. These complications have been taken by some as evidence that there is no counterconditioning process. However, these complications merely make it more difficult to observe counterconditioning; they do not speak directly to the actual occurrence of this phenomenon. The results of the present study, in which the counterconditioning agent was delivered after the forced exposure to the fear stimulus was terminated, clearly reveal a modulatory effect of the new US. By shifting the counterconditioning manipulation from the CS itself to a memory reactivation (or representation) of the CS, several potential methodological complications of the traditional procedure have been precluded. This alternative approach should facilitate further examination of the counterconditioning process as well as provide information on the range of postacquisition events that can modulate memory representations.

\section{REFERENCES}

Amsel, A., \& Roussel, J. (1952). Motivational properties of frustration: I. Effects on a running response of the addition of frustration to the motivational complex. Journal of Experimental Psychology, 43, 363-368.

Bouton, M. E., \& Bolles, R. C. (1979). Contextual control of the extinction of conditioned fear. Learning \& Motivation, 10, 445-466.

Campbell, B. A., Teghtsoonian, R. (1958). Electrical and behavioral effects of different types of shock stimuli on the rat. Journal of Comparative \& Physiological Psychology, 51, 185-192.

Capaldi, E. D., Vivieros, D. M., a Campbell, D. M. (1983). Food as a contextual cue in counterconditioning experiments: Is there a counterconditioning process? Animal Learning \& Behavior, 11, 213-222.

DALY, H. B. (1969). Learning of a hurdle-jump response to escape cues paired with reduced reward or frustrative nonreward. Journal of Experimental Psychology, 79, 146-157.

Davison, G. C. (1968). Systematic desensitization as a counterconditioning process. Journal of Abnormal Psychology, 73, 91-99.

DeARING, M. F., \& DickINSON, A. (1979). Counterconditioning of shock by a water reinforcer in rabbits. Animal Learning \& Behavior, 7, 360-366.

DelPRATo, D. J., JACKSON, D. E. (1973). Counterconditioning and exposure-only in the treatment of specific (conditioned suppression) and generalized fear in rats. Behavior Research \& Therapy, 11, 453-461.

Hunsicker, J. P., Nelson, T. C., \& ReID, L. D. (1973). Two kinds 
of intracranial stimulation as counterconditioners of persisting avoidance in rats. Physiological Psychology, 1, 227-230.

Lovibond, P. F., \& Dickinson, A (1982). Counterconditioning of appetitive and defensive CRs in rabbits. Quarterly Joumal of Experimental Psychology, 34B, 115-126.

McGaugh, J. L. (1966). Time-dependent processes in memory storage. Science, 153, 1351-1358.

Pearce, J. M., \& Dickinson, A. (1975). Pavlovian counterconditioning: Changing the suppressive properties of shock by association with food. Joumal of Experimental Psychology: Animal Behavior Processes, 104, $170-177$.

Reid, L. D. (1973). Processes of fear reduction in systematic desensitization: An addendum to Wilson and Davison. Psychological Bulletin, 79, 107-109.

Rescorla, R. A. (1973). Effect of US habituation following conditioning. Joumal of Comparative \& Physiological Psychology, 82, 137-143.

Rescorla, R. A. (1974). Effect of inflation of the unconditioned stimulus value following conditioning. Journal of Comparative \& Physiological Psychology, 86, 101-106.

Riccio, D. C., \& RichaRdson, R. (1984). The status of memory fol- lowing experimentally induced amnesias: Gone, but not forgotten. Physiological Psychology, 12, 59-72.

Richardson, R., Riccio, D. C., Jamis, M., Skozcen, T., \& Cabosky, J. (1982). Modification of reactivated memory through "counterconditioning. "American Journal of Psychology, 95, 67-84.

Richardson, R., Ruccio, D. C., \& MowreY, H. (1982). Retrograde amnesia for previously acquired Pavlovian conditioning: UCS exposure as a reactivation treatment. Physiological Psychology, 10, 384-390.

Wilson, E. H., \& Dinsmoor, J. A. (1970). Effect of feeding on "fear" as measured by passive avoidance in rats. Journal of Comparative \& Physiological Psychology, 70, 431-436.

WILson, G. T. (1973). Counterconditioning versus forced exposure in extinction of avoidance responding and conditioned fear in rats. Journal of Comparative \& Physiological Psychology, 82, 105-114.

Wilson, G. T., \& DAvison, G. C. (1971). Processes of fear reduction in systematic desensitization: Animal studies. Psychological Bulletin, 76, 1-14.

(Manuscript received September 26, 1985; revision accepted for publication January 29, 1987.)

\section{ERRATUM}

McIsaac, H. P., \& Kreithen, M. L. Attempts to condition homing pigeons to magnetic cues in an outdoor flight cage. Perception \& Psychophysics, 15, 118-123-Please note that the Able (1980) citation on page 119 should be changed to Able (1981). Please also note that the Able reference on page 122 should correctly read:

ABLE, K. (1981). Mechanisms of orientation, navigation, and homing. In S. Gauthreaux (Ed.), Animal migration, orientation, and navigation (pp. 283-373). New York: Academic Press. 